\title{
CORRECTION
}

View Article Online

View Journal | View Issue

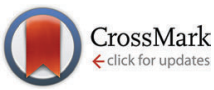

Cite this: J. Mater. Chem. C, 2016, 4, 7508

DOI: $10.1039 /$ c6tc90131j

www.rsc.org/MaterialsC

\section{Correction: Evaluating the role of energetic disorder and thermal activation in exciton transport}

\author{
Thomas R. Fielitz, $\uparrow$ S. Matthew Menke $\ddagger$ and Russell J. Holmes*
}

Correction for 'Evaluating the role of energetic disorder and thermal activation in exciton transport' by S. Matthew Menke et al., J. Mater. Chem. C, 2016, 4, 3437-3442.

There is a mistake in the distance dependence of eqn (4), which should read:

$$
\Gamma\left[E, E^{\prime}, d\right]=\frac{R_{0, \mathrm{C}^{6}}}{d^{6} \tau_{\mathrm{rad}}} \exp \left(-\frac{E_{\mathrm{A}}}{k T}\right) \exp \left(-\frac{E^{\prime}-E}{k T}\right)
$$

There are also errors in Table 1 on page 3440, which affect four callouts from the main text. In Table 1, the second column, " $R_{0, \mathrm{C}} 6 / \tau_{\mathrm{rad}}\left[\mathrm{nm}^{6} \mathrm{~ns}^{-1}\right]$ " is actually " $R_{0, \mathrm{C}} / \tau_{\mathrm{rad}}{ }^{1 / 6}\left[\mathrm{~nm} \mathrm{~ns}^{-1 / 6}\right]$ ". This correction only changes the second column title and the seventh column values (" $R_{0, \mathrm{C}}$ ") and the corrected table is given below:

Table 1 Model parameters for the KMC simulations predicting the temperature dependence of $L_{\mathrm{D}}$. Here, $R_{0, \mathrm{C}} / \tau_{\mathrm{rad}}{ }^{1 / 6}, E_{\mathrm{A}}$, and $\sigma$ are fitting parameters for the KMC simulations. The $\eta_{\mathrm{PL}}$ is separately measured allowing for the tabulation of $\tau_{\text {rad }}$ and extraction of $R_{0, \mathrm{C}}$ from the fit parameters. Shown for comparison is the average molecular separation $(d)$ determined from the thin-film density $(\rho)$ as $d=\sqrt[3]{3 /(4 \pi \rho)}$

\begin{tabular}{llllclll}
\hline Material & $R_{0, \mathrm{C}} / \tau_{\mathrm{rad}^{1 / 6}}\left[\mathrm{~nm} \mathrm{~ns}^{-1 / 6}\right]$ & $E_{\mathrm{A}}[\mathrm{meV}]$ & $\sigma[\mathrm{meV}]$ & $\eta_{\mathrm{PL}}[\%]$ & $\tau_{\mathrm{rad}}[\mathrm{ns}]$ & $R_{0, \mathrm{C}}[\mathrm{nm}]$ & $d[\mathrm{~nm}]$ \\
\hline Alq $_{3}$ & 2.3 & $<10$ & 150 & 16.2 & 99 & 5.0 & 0.53 \\
DCV3T & 1.7 & 80 & 33 & 8.0 & 17 & 2.7 & 0.54 \\
SubPc & 1.4 & $<10$ & 35 & 1.0 & 55 & 2.7 & 0.48 \\
\hline
\end{tabular}

For consistency, all references to the fitting parameter $R_{0, \mathrm{C}}{ }^{6} / \tau_{\text {rad }}$ must also be changed to $R_{0, \mathrm{C}} / \tau_{\text {rad }}{ }^{1 / 6}$. This occurs on page 3439 , column 1, line 13; page 3439, column 2, line 3; page 3439, column 2, line 18; and page 3440 in the caption of Fig. 4 , line 6.

The Royal Society of Chemistry apologises for these errors and any consequent inconvenience to authors and readers. 